\title{
INTERPRETATION OF STRESS-STRAIN CURVE IN PIPELINE RESEARCH
}

\author{
J.-B.Wellekens ${ }^{1}$, W. De Waele ${ }^{2}$, R. Denys ${ }^{2}$, S. Hertelé ${ }^{2}$ and M. Verstraete ${ }^{2}$ \\ ${ }^{1}$ Ghent University, Belgium \\ ${ }^{2}$ Ghent University, Laboratory Soete, Belgium
}

\begin{abstract}
For the design of on-shore pipelines installed in areas that are susceptible to ground movements and offshore pipelines, axial stresses above yield must be considered. In such so-called strain-based design, knowledge of the stress-strain behaviour of the pipeline steel and girth welds is highly important. These behaviours are influenced by many factors, including: welding parameters, operation temperature, tensile test specimen geometry and orientation, and microstructure of the steel. This paper focuses on the influence of the tensile test specimen geometry and orientation, for the case of UOE formed pipes. As regards the geometry, it is concluded that the stress-strain diagram is most representative for a flat fullthickness test specimen. As regards the orientation, the yield stress is higher for transversal test specimens, as compared to longitudinally oriented test specimens.
\end{abstract}

Keywords pipeline steels, strain-based design, stress-strain curve, UOE, microstructure, anisotropy

\section{INTRODUCTION}

The mechanical properties of pipeline steels change during plate production and subsequent pipe forming. First, the rolling process is a source of anisotropy, producing differences in stress-strain behaviour between the directions parallel and perpendicular to the rolling direction. Second, pipes can be produced from flat plates in different ways. This paper focuses on the UOE process, illustrated in Figure 1. It is performed by three press processes (edge crimping press, U-ing press, O-ing press), followed by seam welding and a circumferential expansion [1]. Obviously, this cold forming process produces changes in the mechanical properties of the used steel.

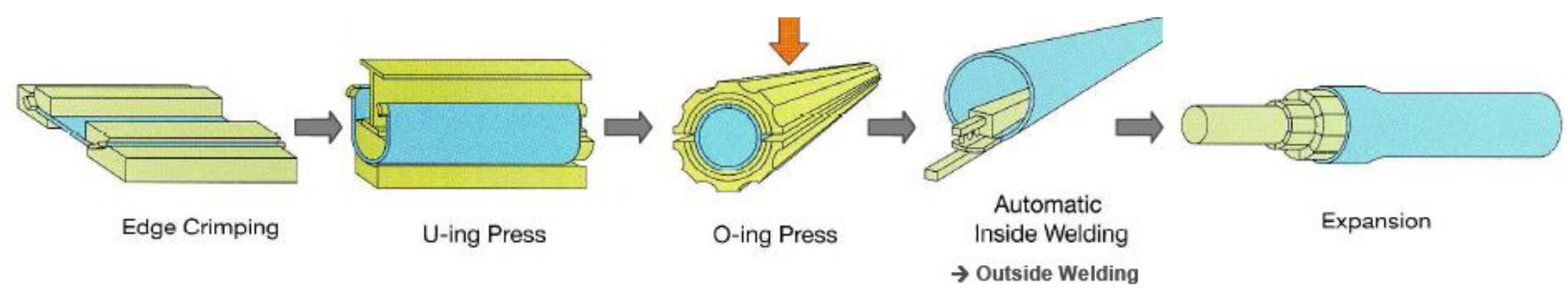

Fig. 1: Schematic illustration of production of UOE pipe.

The stress-strain behaviour of a steel is generally characterized by a tensile test. This paper discusses, for the specific case of UOE-formed pipes, the influence of test specimen geometry and orientation on the measured stress-strain behaviour.

\section{GEOMETRY OF THE TENSILE TEST SPECIMEN}

As regards common geometries of tensile test specimens in the pipeline industry, a distinction can be made between a round bar and a flat strap (full thickness) specimen.

Looking at a round bar specimen, the measured yield stress (YS) depends on the specimen diameter. This diameter is usually much smaller than the plate thickness, and thereby merely produces a measurement of local properties. This effect is pronounced for round bar specimens of girth welds, since these welds show a large degree of heterogeneity. Indeed, a weldment mostly consists of several weld runs, producing a mixture of coarse and fine microstructures. This results in heterogeneity in the thickness direction (Figure 2, above, [2]) and in the circumferential ('o' clock) direction (Figure 2, below, [3]). In the base metal, the microstructure also varies in the thickness direction. This phenomenon is due to the inhomogeneous cooling during plate production after rolling. 


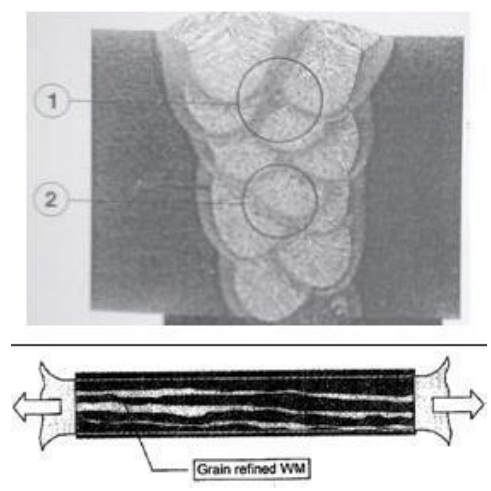

Fig. 2: Variations in the microstructure of a round bar tensile specimen, taken from a pipeline girth weld. Above: thickness direction [2], Below: circumferential ('o' clock) direction [3].

Considering the abovementioned, round bar specimens may produce stress-strain curves with limited representativeness in terms of the global structural behaviour. Therefore, to obtain an average value of strength properties throughout the entire thickness of the pipe, flat strap specimens of full pipe thickness are advised. This conclusion should, however, be nuanced for transversally oriented test specimens, since full thickness specimens have to be flattened in that case (see section 3.1).

\section{ORIENTATION OF THE TENSILE TEST SPECIMEN}

Several investigations reveal that the mechanical properties of pipeline steels are highly dependent on the orientation of the tensile test specimens, relative to the pipe axis. A distinction can be made between transversally (perpendicular to the pipe axis) and longitudinally (parallel to the pipe axis) oriented specimens. This observed heterogeneity is due to the steel rolling process, as well as the UOE pipe forming process. Asahi et al. [4] found that both yield stress and ultimate tensile stress in transversal and longitudinal direction are higher than their respective values of the original flat plate (Fig. 3). Differences between the transversally and the longitudinally oriented specimens are further discussed below.
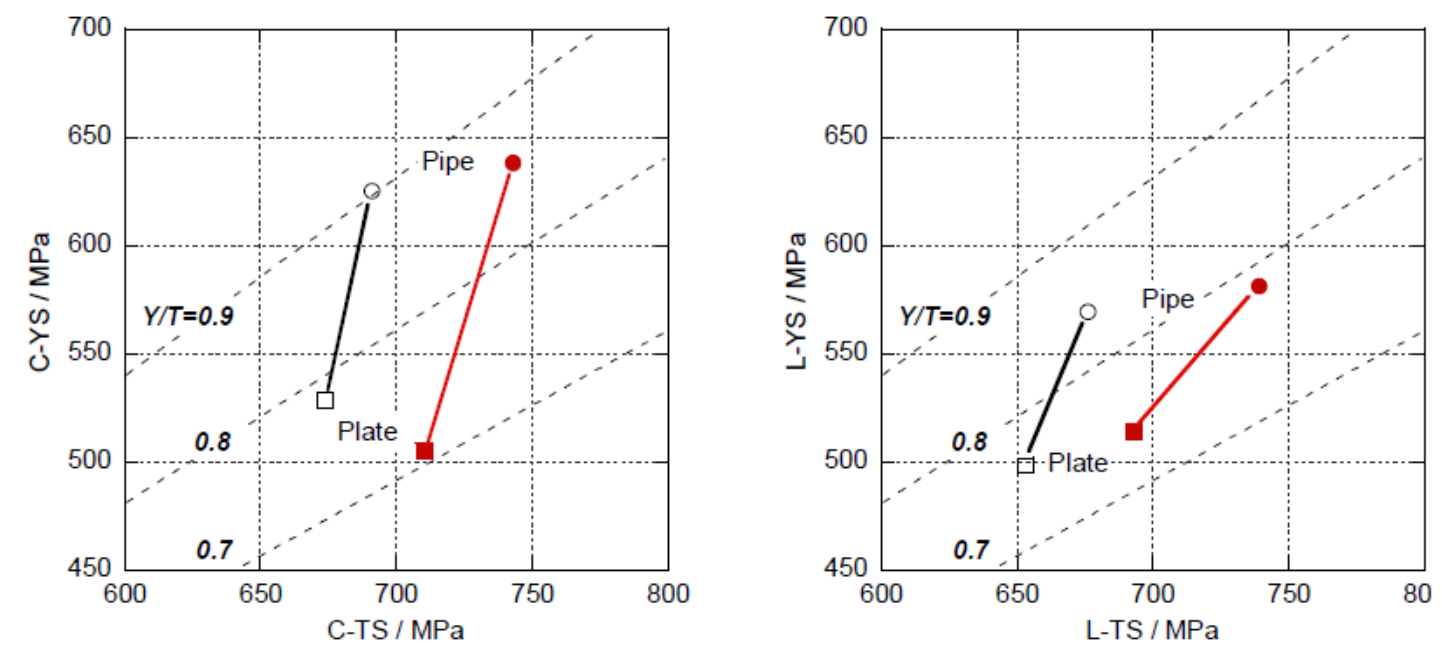

Fig. 3: Both yield stress and ultimate tensile stress increase due to UOE pipe forming [4]. Left: circumferential direction; right: longitudinal direction.

\subsection{Transversally oriented specimen specimen}

For the determination of the tensile properties of pipeline steels in the transversal direction, three methods can be applied: round bar specimens, flat strip specimens, and the ring expansion method. The flat strip specimen is in this case flattened, since a pipe is curved in the transversal direction. In the ring expansion method, a ring is taken from the pipeline and subjected to a radial expansion.

Several studies have shown that the flat strip specimens produce lower yield strengths than the round bar and ring expansion specimens [5-11] (Fig. 4 [10]). This effect can be assigned to the Bauschinger effect that occurs during the flattening of the strip specimen, as explained below. 


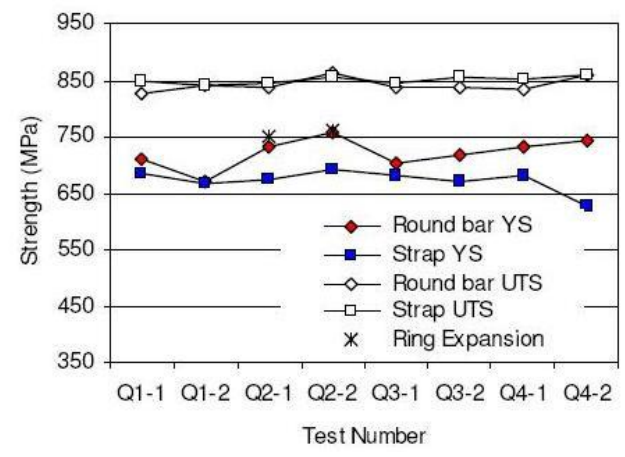

Fig. 4: A comparison of round bar, flat strip (strap) and ring expansion tensile test results [10].

During the cold forming of steel plate to its pipe configuration, the mechanical properties change at every point, due to a location-specific deformation cycle. A part of the plate undergoes a tensile load $(A \rightarrow B$ in Fig. 5). Then, in case of a flattened strip specimen, a second deformation cycle is imposed due to flattening. The material that saw a tensile cycle during pipe forming, is now subjected to a compression (B $\rightarrow$ D). If, eventually, the test specimen is subjected to a tensile test ( $\left.\rightarrow C^{\prime}\right)$, it can be seen that the yield strength has decreased from $A$ (original plate) to $A^{\prime}$ (flattened strip specimen). [12-15].

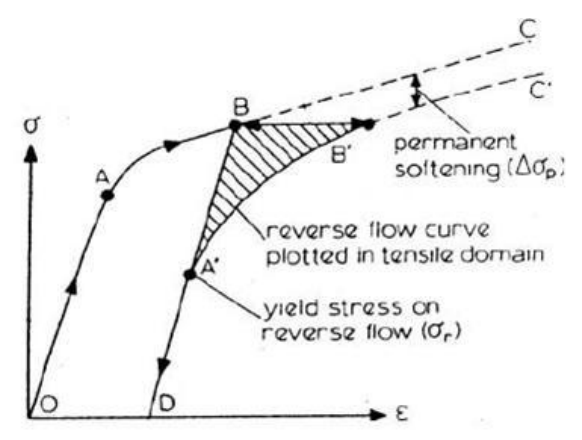

Fig. 5: Illustration of the Bauschinger effect.

Fig. 4 indicates that the yield stresses of a round bar test are similar to those of a ring expansion test. These values are, for transversally oriented specimens, considered the most representative. Preference is given to the round bar specimen, since this method imposes less practical issues than the ring expansion method.

\subsection{Longitudinally oriented specimen}

In order to determine the strength-properties in the longitudinal direction, two specimens are commonly used: the round-bar specimen and rectangular bar covering the full wall thickness. From Fig. 6 [10] it can be noted that the kind of test specimen has an influence on the measured yield and tensile strength. This variation originates from the microstructure tested. Using a rectangular bar, the testing is performed on a section containing both the coarse and fine grained microstructure which is found in the through thickness direction. On the other hand, the use of a round-bar specimen results in the testing of a section less than the wall thickness. This means it is susceptible to the local properties, depending on the position of the round bar specimen, another microstructure will be tested. Testing a fine grained section will unambiguous result in a higher measured yield and tensile strength, whilst a coarse microstructure will lead to a deterioration of the measured properties $[6,8,9,11,16]$.

Therefore it is recommended to use a rectangular test specimen covering the full wall thickness. This will result in more representative measured data compared to the full pipe behavior. Besides, the preparation of a round-bar specimen requires a higher work load than the preparation of a rectangular bar. 


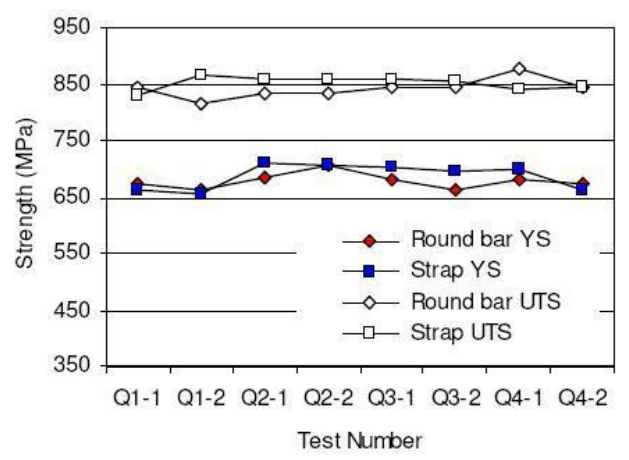

Fig. 6: Results of tensile tests on longitudinally oriented specimens [10].

The presence of anisotropy is also worth mentioning. From Fig. 7 a clear difference can be seen between the measured yield strength of a longitudinal and transversal round bar specimen. On the other hand, the tensile strength is comparable for both directions. This difference has most probably originated from the different amount of cold work in these two directions. Due to the pipe forming process, the yield strength of the material might increase [4, 16-30]. Another sort of anisotropy is noted in the right part of Fig. 7. From the elliptical shape of the fractured area it can be seen that the post-yield behavior in the thickness direction differs from the behavior in the testing direction.
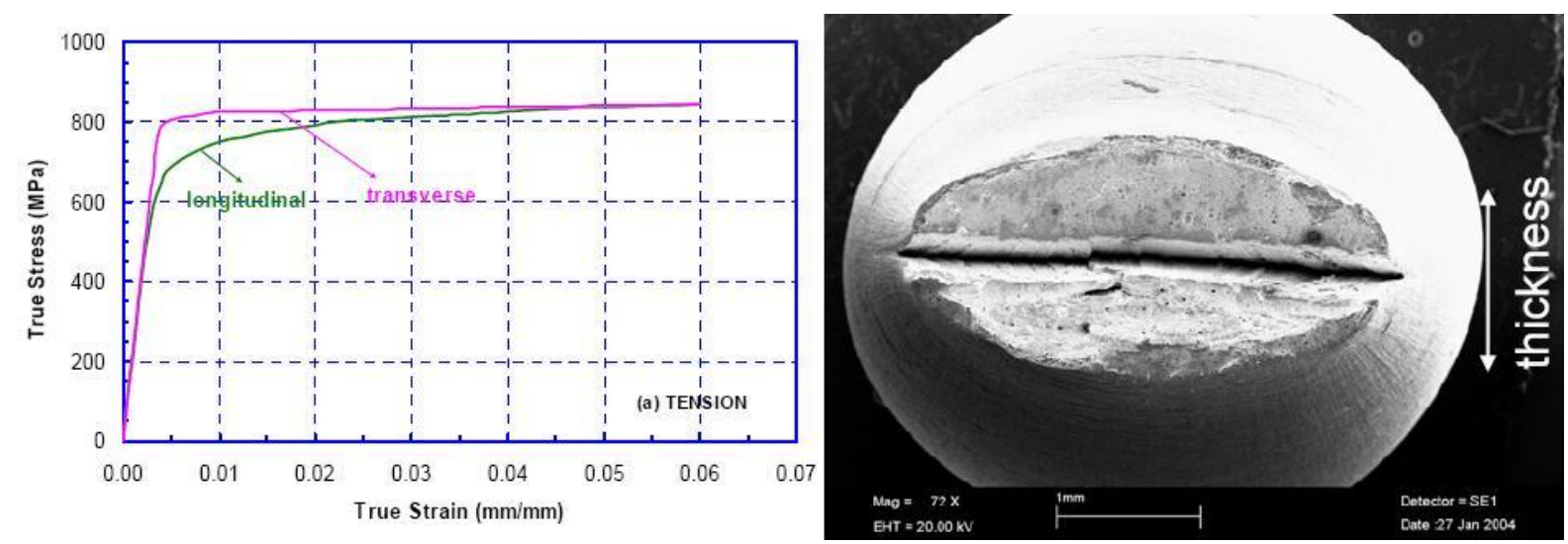

Fig. 7: Stress-strain behaviour of an X100 pipeline steel [17].

\section{CONCLUSIONS}

Defining the mechanical properties of pipeline steels is not straight forward. An overall picture cannot easily be provided since many factors affect the final tensile properties of pipeline steels. Therefore the testing conditions may never be neglected when the results are discussed.

From the literature review, it can be concluded that the use of a full thickness test specimen is more representative and less susceptible to scatter than a round-bar specimen, which only covers part of the wall thickness. Furthermore, the test specimen should not be subjected to any unnecessary plastic deformation during the testing phase, in order to keep the measured strength properties as close as possible to the full pipe behavior. 


\title{
5 NOMENCLATURE
}

\author{
YS yield strengh \\ UTS Ultimate Tensile Strength \\ Y/T Yield to Tensile ratio \\ WM Weld Material \\ BM Base Material
}

\section{REFERENCES}

[1] K. Nagai, Y. Shinohara, S. Sakamoto, E. Tsuru, H. Asahi, T. Hara, Anistropic Strain Aging Behavior of High Strength UOE Linepipe, Proceedings of the Nineteenth International Offshore and Polar Engineering Conference, 56-60, Osaka, Japan, June 21-26, 2009.

[2] R. Denys, Testing for weld metal yield strength, Mis-Matching of Welds, ESIS17 (Edited by K.-H. Schwalbe and M.Koçak), Mechanical Engineering Publications, 777-787, London, UK, 1994.

[3] R. Denys, Weld Metal Strength Mismatch: Past, Present, and Future, Osaka, May 16,jaartal

[4] H. Asahi, T. Hara, E. Tsuru, H. Morimoto, Development and commercialization of high-strength linepipe, Procedings of the Pipeline Technology Conference, Ostend, Belgium, October 12-14, 2009.

[5] M. Hamada, S. Okaguchi, H. Shitamoto, Y. Komizo, Tensile properties and deformation behaviour at the weld position of X100 line pipe steel, Proceedings of the Pipe Dreamer's Conference, Pacifico Yokohama, Japan, November 7-8, 2002.

[6] H. Asahi, T. Hara, E. Tsuru, H. Morimoto, et al., Development and Properties of Ultra-High Strength UOE Linepipe, Proceedings of the International Pipeline Conference, Calgary, Canada, October 48,2004

[7] H. Asahi, T. Hara, E. Tsuru, H. Morimoto, et al., X120 UOE Linepipe With Improved Properties and Varied Sizes, Proceedings of the International Pipeline Conference, Calgary, Canada, September 25-29, 2006.

[8] Z. Xiaoli, Z. Chuanjing, J. Lingkang, F. Yaorong, Z. Wenzhen, H. Chunyong, Z. Xinwei, G. Shaotao, The micro structural characteristic parameters of high grade pipeline steel and its mechanical properties, Proceedings of the International Pipeline Conference, Calgary, Canada, September 2529, 2006.

[9] H. Hillenbrand, A. Liessem, F. Grimpe, V. Schwinn, Manufacturing of X100 Pipes for the TAP project, Proceedings of the International Pipeline Conference, Calgary, Canada, September 25-29, 2006.

[10] R. Klein, L. Collins, F. Hamad, X. Chen, D. Bai, Determination of Mechanical Properties of High Strength Linepipe, Proceedings of the International Pipeline Conference, Calgary, Canada, September 29 - October 3, 2008.

[11] J. Johnson, M. Hudson, N. Takahashi, M. Nagase, A. Yamamoto, Specification and Manufacturing of Pipes for the X100 Operational Trial, Proceedings of the International Pipeline Conference, Calgary, Canada, September 29 - October 3, 2008.

[12] P. Verleysen, Modellering van Mechanisch Materiaalgedrag Partim: Plasticiteit en Visco-elasticiteit, Ghent, Belgium, 2008.

[13] J.B. Winkel, M. Rieder, H. Henein, T. Schulz, Effect of Material Characteristics on the Properties of a Steel Pipe, Proceedings of the $4^{\text {th }}$ International Pipeline Conference, Calgary, Canada, September 29 - October 3, 2002.

[14] J.B. Winkel, M. Rieder, H. Henein, Evolution of the Bauschinger Effect During Fabrication of MicroAlloyed Pipeline Steels, Proceedings of the International Pipeline Conference, Calgary, Canada, October 4-8, 2004.

[15] P. Thibaux, D. Van Hoecke, G. De Vos, Influence of Forming and Flattening on the Measured Tensile Properties of Linepipe, Proceedings of the International Pipeline Conference, Calgary, Canada, September 25-29, 2006.

[16] H. Chen, L. Ji, Y. Feng, W. Xie, Strain Aging Effect on Mechanical Properties of X80 High Strength Line Pipe, Procedings of the Pipeline Technology Conference, Ostend, Belgium, October 12-14, 2009.

[17] Y.-Y. Wang, M. Liu, The Role of Anisotropy, Toughness Transferability, and Weld Misalignment in the Strain Based Design of Pipelines, Proceedings of the Seventeenth International Offshore and Polar Engineering Conference, Lisbon, Portugal, July 1-6, 2007.

[18] L. Ji, X. Li, H. Chen, C. Y. Huo, S. Gong, X. Zhao, On the Relationship between Yield Ratio, uniform Elongation, and Strain Hardening Exponent of High Grade Pipeline Steels, Proceedings of 
the Seventeenth International Offshore and Polar Engineering Conference, Lisbon, Portugal, July 16, 2007.

[19] Y.-Y. Wang, M. Liu, D. Rudland, D. Horsley, Strain Based Design of High Strength Pipelines, Proceedings of the Seventeenth International Offshore and Polar Engineering Conference, Lisbon, Portugal, July 1-6, 2007.

[20] J.M. Treinen, W.E. Luecke, J.D. McColskey, P.P. Darcis, Y.-Y. Wang, Anisotropic Behavior of X100 Pipeline Steel, Proceedings of the Eighteenth (2008) International Offshore and Polar Engineering Conference, Vancouver, BC, Canada, July 6-11, 2008.

[21] D.-H. Seo, J.-Y. Yoo, W.-H. Song, K.-B. Kang, Development of X100 Linepipe Steel with High Deformation Capacity, Proceedings of the 7th International Pipeline Conference, Calgary, Canada, September 29-October 3, 2008.

[22] D.-M. Duan, J. Zhou, B. Rothwell, D. Horsley, N. Pussegoda, Strain Aging Effects in High Strength Line Pipe Materials, Proceedings of the 7th International Pipeline Conference, Calgary, Canada, September 29-October 3, 2008.

[23] N. Ishikawa, M. Okatsu, S. Endo, J. Kondo, J. Zhou, D. Taylor, Mass Production and Installation of X100 Linepipe for Strain-Based Design Application, Proceedings of the 7th International Pipeline Conference, Calgary, Canada, September 29-October 3, 2008.

[24] I. Takeuchi, Property of X80 Grade SAW Pipes For Resistance to Ground Movement, Proceedings of the 7th International Pipeline Conference, Calgary, Canada, September 29-October 3, 2008.

[25] A. Liessem, G. Knauf J. Schröder, S. Zimmermann, M. Pant, C. Stallybrass, et al., Investigation of the Stress-Strain Behaviour of Large-Diameter X100 Linepipe in View of Strain-Based Design Requirements, Proceedings of the 7th International Pipeline Conference, Calgary, Canada, September 29-October 3, 2008.

[26] T. Yoshida, T. Terasava, T. Hara, A. Tsuru, H. Morimoto, Establishment of Commercial Production for High Strength UOE Linepipe up to X120, Proceedings of the Nineteenth International Offshore and Polar Engineering Conference, Osaka, Japan, June 21-26, 2009.

[27] H.-G. Hillenbrand, C. Kalwa, J. Schroeder, Meeting Highest Requirements for the Challenge of the Nord Stream Project, Procedings of the Pipeline Technology Conference, Ostend, Belgium, October 12-14, 2009.

[28] A. Liessem, R. Rueter, M. Pant, V. Schwinn, Production and Development Update of X100 for Strain-Based Design Application, Procedings of the Pipeline Technology Conference, Ostend, Belgium, October 12-14, 2009.

[29] E.Tsuru, Y. Shinohara, J. Agata,H. Asahi, Dominant Factors for Buckling Resistance of UOE Linepipe Used in Strain-Based Design, Procedings of the Pipeline Technology Conference, Ostend, Belgium, October 12-14, 2009.

[30] H. Shitamoto, M. Hamada, S. Okaguchi, N. Takahashi, N. Yamamoto, I. Takeuchi, S. Fujita, Effect of Thermal Aging on Deformability of X80<SAW Pipes, Procedings of the Pipeline Technology Conference, Ostend, Belgium, October 12-14, 2009. 